\title{
Lexical Availability Output in L2 and L3 EFL Learners: Is There a Difference?
}

\author{
Rosa M ${ }^{\mathrm{a}}$ Jiménez Catalán $^{1}$ \& Almudena Fernández Fontecha ${ }^{1}$ \\ ${ }^{1}$ University of La Rioja, Spain \\ Correspondence: Rosa $\mathrm{M}^{\mathrm{a}}$ Jiménez Catalán, Facultad de Letras y Educación, Departmento de Filologías \\ Modernas, C/ San José de Calasanz s/n, 26004 Logroño, La Rioja, Spain.
}

Received: September 26, 2018

Accepted: January 6, 2019 Online Published: January 9, 2019

doi: $10.5539 /$ elt.v12n2p77

URL: https://doi.org/10.5539/elt.v12n2p77

\begin{abstract}
English as a foreign language (EFL) is a global issue that extends to thousands of learners worldwide who share a similar classroom situation. However, researchers have often considered learners to have homogeneous linguistic profiles, overlooking the fact that EFL classrooms in primary and secondary education include learners with different linguistic profiles. Despite the fact that immigrant and non-immigrant students meet every day in classrooms, little is known about the EFL performance of the former compared to the latter. This paper addresses this reality, and explores the vocabulary performance of immigrant students, learners of English as an L3, compared to learners of English as an L2 who had the same course level and were from the same community. The research questions were twofold:

(1) to ascertain whether there were quantitative differences between L2 and L3 English learners in terms of the number of words produced by each group, and

(2) to ascertain whether there were qualitative differences in the words produced by the L3 and L2 groups with regard to (a) the most and least productive prompts for each group, and (b) the number of infrequent words appearing in the production of each group.

The sample consisted of 14 bilingual students who were learners of English as an L3 and 14 monolingual learners of English as an L2, respectively, who were in the twelfth year of Spanish secondary education (age 17-18 years old). The data collection instrument was a lexical availability task consisting of six prompts. The data were lemmatized, coded and analysed by means of WordSmith Tools and the VocabProfile programme. The results indicated that the L2 group produced a greater number of words and a higher percentage of infrequent words in the most productive prompt.
\end{abstract}

Keywords: Lexical availability output, English as a third language, immigrant EFL learners, multilingualism in school contexts, lexical sophistication, lexical frequency profile

\section{Introduction}

Lexical availability is defined as the words that come to mind in response to topics related to daily situations, such as when we need to talk about food and drink in a restaurant, or to talk about subjects, teaching materials or classroom management at school (Richards \& Schmidt, 2010). The study of the lexical availability of learners of English as a foreign language (EFL) is of foremost importance for teachers and researchers. Firstly, it reveals the English words that learners have in their mental lexicons in relation to different semantic fields at different educational stages. Secondly, it unveils information about the factors that may influence lexical retrieval and production in the target language. Thirdly, the words produced in association with prompts related to daily issues and realities may reveal how EFL learners see themselves and others. Finally, lexical availability studies provide relevant data regarding the vocabulary performance of groups with different linguistic profiles. However, the number of lexical availability studies of EFL learners is limited, and such studies have generally been concerned with studying the effect of age, gender and type of instruction (Jiménez Catalán, 2017) rather than comparing the lexical output of immigrant and non-immigrant students who are learners of English as third and second languages, respectively in EFL classrooms.

EFL is a global issue that extends to thousands of learners worldwide who share a similar classroom situation, even if they live in distant countries such as Spain, Russia, Iran and Japan. In these countries, English is taught 
as part of the schools' curricula via programmes and objectives, textbooks, exams and the allocation of marks, and the target language is not used in the community for daily communication. English language learning and instruction has been the concern of researchers for decades. However, numerous studies have assumed that learners have had homogeneous linguistic profiles, overlooking the fact that EFL classrooms in primary and secondary education include learners with different linguistic profiles. This is the case of La Rioja, a monolingual community in which Spanish is the language of institutions and schooling. However, the official monolingualism hides a multilingual reality built upon the frequent hosting of immigrants from European as well as non-European countries, whose first language is different from Spanish. Current primary and secondary schools in La Rioja confirmed a multilingual landscape of linguistic profiles. They range from native Spanish students for whom English was a second language (L2), to immigrant students who had native competence in two languages: the family language (L1), and the language of the host community and schooling (Spanish in this study), and for whom English is their third language (L3). The processes of learning a third language differs from learning a second language because, in the former case, learners benefit from the experience of having learnt another language either simultaneously or consecutively with their L1 (Cenoz, 2001; Wei, 2003; Jessner, 2008). However, as Cenoz (2003, p.3) observed, there is considerable research on the effect of bilingualism on cognitive development, but "the particular effect of bilingualism on subsequent language learning has not received much attention." Similarly, as Maluch et al. (2015) observed, how bilingualism resulting from immigration affects foreign language learning is unclear. Despite the fact that immigrant and non-immigrant students meet in classrooms every day, little is known about the EFL performance of the former compared to the latter. This is surprising if we consider the spread of immigration and the fact that, regardless of the learners' origins, English is compulsory throughout six years of primary education, four years of secondary education, and two of post-obligatory education. The current study addresses this reality and focuses on the lexical availability output in English as the L3 of immigrant students who are bilingual in two languages (family language + Spanish) in comparison to Spanish monolingual students for whom English becomes their L2. To achieve this objective, our literature review will be centred on vocabulary performance in English as an L3 compared to as an L2.

\subsection{Literature Review}

We will consider three parameters in the revision: focus, instruments and the backgrounds of the participants. In addition to providing a synthesis of the outcomes, the application of these criteria to each study under examination will provide us with the basis for the comparison and discussion of our results in the light of previous research.

Research on L3 acquisition is scarce, particularly as far as vocabulary is concerned. Table 1 includes the main studies on vocabulary published in journals thus far. However, even if they are not numerous, it is already possible to observe some trends. One is the focus on receptive vocabulary knowledge and cross-linguistic influence, addressed by means of the Vocabulary Levels Test and translation tasks, respectively (e.g. Kassaian \& Esmae'li, 2011; Keshavarz \& Astaneh 2004; Molnár, 2018; Thomas, 1998). The focus on productive vocabulary as a dimension of knowledge on its own is almost entirely absent in L3 language studies, and lexical availability, which can be considered as both production and association, is represented by just one study (e.g. Agustín Llach, 2017). Another tendency that can be observed is the predominance of studies with bilingual profiles drawn from natural contexts in which the languages are used in a minority situation in some geographical areas of the countries in which the research was conducted (e.g. Agustín Llach, 2007; Chezlou, Kosha, \& Lotfi, 2018; Dibaj, 2011).

Table 1. Vocabulary studies in English as an L3 versus English as an L2

\begin{tabular}{llll}
\hline Study & Focus & Instruments & Participants' backgrounds \\
\hline Ghezlou, & Adjective & Translation test & 90 Azeri-Persian EFL learners \\
Koosha, & placement & PET (2015 version) & Persian EFL Learners \\
and Lotfi & Cross-linguistic & Background & Iran \\
$\mathbf{2 0 1 8}$ & influence & questionnaire & University \\
\hline
\end{tabular}




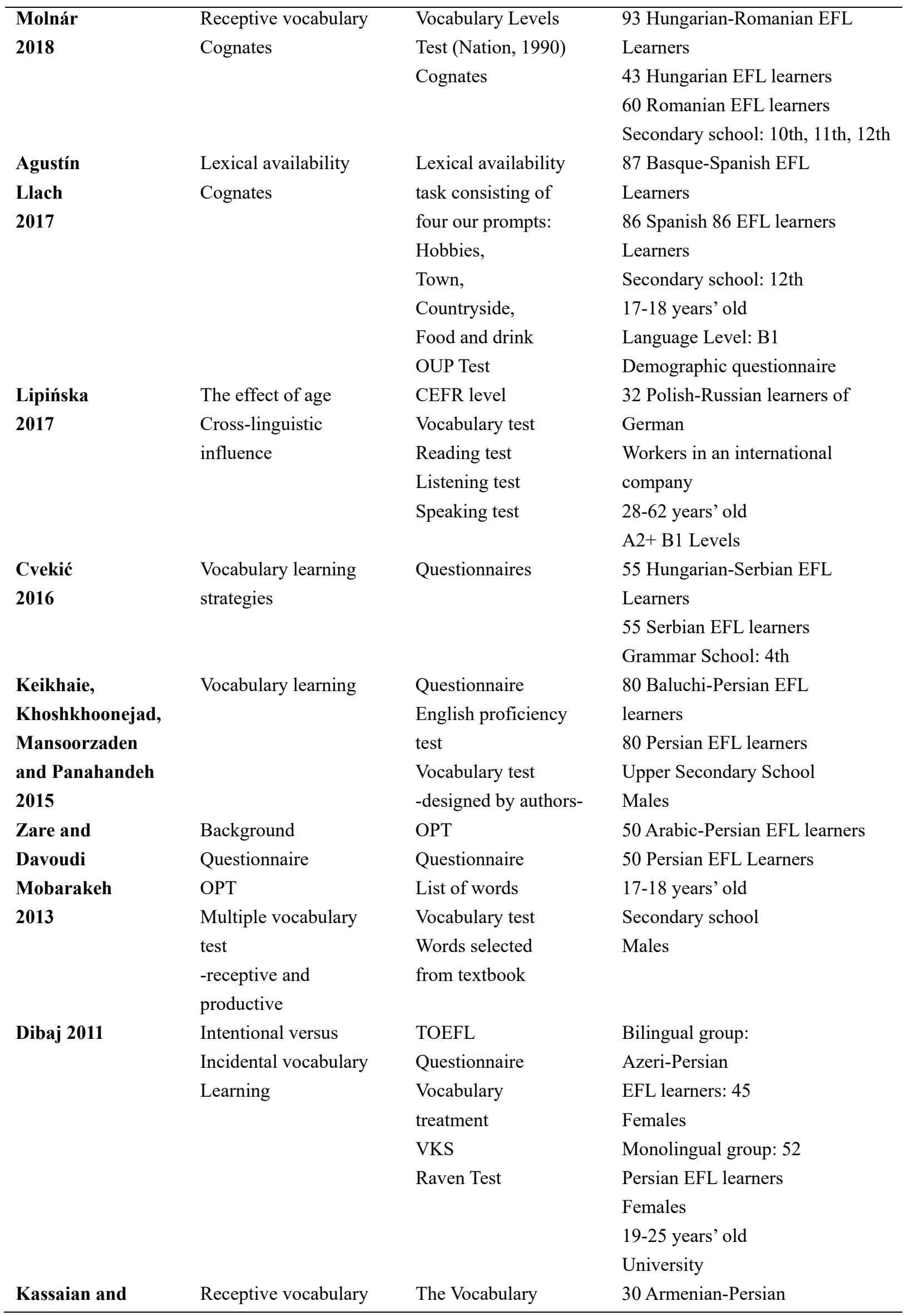




\begin{tabular}{llll}
\hline Esmae'li & Reading & Levels Test & bilinguals versus \\
$\mathbf{2 0 1 1}$ & & (Nation, 1983; & 30 Persian monolinguals \\
& & Schmidt et al. & Iranian female EFL learners \\
& $2001)$ & $17-18$ years' old \\
& & Word Reading Test & Lower intermediate \\
& & OUP Test & \\
& & 30 Turkish-Persian bilinguals, \\
Keshavarz and & Receptive vocabulary & The Vocabulary & 30 Armenian-Persian bilinguals, \\
Astaneh & & Levels Test & 30 Persian monolinguals \\
$\mathbf{2 0 0 4}$ & & (Laufer and Nation & Iranian female EFL learners \\
& & $1990)$ & $17-18$ years' old \\
Cenoz & & 90 Basque-Spanish EFL learners \\
$\mathbf{2 0 0 1}$ & Age & Picture story: 'Frog & Elementary and Secondary \\
& Cross-linguistic & where are you?' & School: 6th and 9th grade \\
& influence & Background & \\
Thomas & Ruestionnaire & 16 English-Spanish French \\
$\mathbf{1 9 8 8}$ & Receptive/productive & Translation test & learners \\
& Vocabulary & Grammar test & 10 English monolingual French \\
& Cognates & MLA test & Learners \\
& & Motivation & Elementary French \\
& & Questionnaire & University \\
\hline
\end{tabular}

With regard to the results obtained, bilingual groups achieved better scores in vocabulary tests in English L3 (see Dibaj, 2011; Kassaian \& Esmae'li, 2011; Keikhaie, Khoshkhoonejad, \& Panahandeh, 2015; Keshavarz \& Astaneh, 2004; Molnár, 2018; Zare \& Davoudi-Mobarakeh, 2013). However, Zare and Davoudi-Mobarakeh (2013) found significant differences in favour of the bilingual group only in the translation task, but not in the vocabulary receptive task. Similarly, counter-evidence was found in the study conducted by Ghezlou, Koosha and Lotfi (2018), in which they compared vocabulary production in English as an L3 and as an L2 by means of a translation task. The Persian monolingual group obtained significantly better results than did the Azeri-Persian bilingual group. This was explained on the basis of the latter being subtractive bilingualism with L1 Azeri speakers as minority groups in comparison to Persian speakers.

As to cross-linguistic influences, a facilitating effect of the L2 on English as the L3 was reported in studies with different combinations of languages, such as bilingual Hungarian-Romanian (Molnár, 2018), or Basque-Spanish (Cenoz, 2001). However, the study by Agustín Llach (2017) on Basque-Spanish bilinguals, as well as the one by Ghezlou, Koosha and Lotfi (2018) on Azeri-Persian bilinguals, revealed that the results were not particularly different from those of monolinguals in terms of cognates and the placement of adjectives, respectively. In addition, the results by Lipińska (2017) provide counter-evidence, as she found "negative language transfer in learning German as an L3, but L2-Russian did not affect the process of TLA in this way". A lack of differences between the L3 and L2 groups were also reported by Cvekić (2016) regarding the perception of the use of vocabulary learning strategies with the bilingual and the monolingual groups showing similar preferences. In summary, comparative studies between L3 and L2 regarding vocabulary show the advantage of bilingual groups over monolinguals, as well as the facilitating effect of the L2 on the L3. Nevertheless, the counter-evidence found, and the fact that most research thus far has been conducted in natural contexts in which two languages coexist rather than in schools and communities with one official language, makes the generalisation of results problematic. The current study seeks to contribute to filling the gap in studies of the vocabulary performance in English as an L3 and as an L2 in a region in which bilingualism does not exist officially, but in which it is a reality in schools because of the hosting of Moroccan and Romanian families, among other nationalities, who educate their children in their home language and in Spanish. Our community has been recurrently hosting a greater number of immigrants. The current study compares the lexical availability output in English as the L3 of bilingual students (family language + Spanish) in comparison to Spanish monolingual students, for whom 
English is their L2. In this way, and in addition to contributing to lexical availability research, the present study aims to respond to the need for research on the English performance of immigrant students to identify whether their bilingualism facilitates the learning of English as an L3, as shown by a higher vocabulary production than that of non-immigrant students in a lexical availability task, as well as to ascertain whether there are similarities or differences in the learning of English as an L3 and as an L2 as observed by the complexity of the words that both groups of EFL learners produced in a lexical availability task. The specific research questions are as follows:

(1) Do learners of English as L3 produce a higher number of English words than do learners of English as L2?

(2) Are there any differences in the quality of the words produced by L3 and L2 EFL learners?

\section{Method}

\subsection{Participants}

The participants in this cross-sectional study were 14 bilingual students who were learners of English as an L3, and 14 monolingual learners of English as an L2, respectively, in the twelfth grade. Both groups were in the same age range (17-18 years old). The curriculum for the twelfth grade in the high schools in which this study was conducted follows the official guidelines set by the government of the community of La Rioja, which has the autonomy to regulate the distribution of the hours of English instruction, as well as the level to be attained at the end of each course. Their level in English, as reported by the teachers, was B1, in accordance with the official level established for the twelfth grade by the educational board of the community. The monolingual sample was selected at random from a large pool of students enrolled in six state high schools in La Rioja in the school year 2015-16. The bilingual sample consists of all the immigrant students studying in these schools during that year. According to the report by the Spanish Ministerio de Educación y Formación Profesional (Secretaría General Técnica, 2017, p.8) for the academic year of 2015/16, La Rioja occupied the second position in the distribution of immigrant students ernrolled in Spanish schools. A total of 400 immigrant students were enrolled in the twelfth grade in La Rioja. This figure includes both immigrants from Latin American countries whose mother tongue is Spanish, and immigrant students from European and non-European countries, approximately fifty per cent of the entire population of immigrants enrolled in the twelfth grade. According to the information provided by the teachers and headmasters from the schools where the data collection took place, most of these students were first generation immigrants; that is, they were born abroad and schooled in Spanish during their primary education. Our sample is representative of this group within the six upper secondary schools in which the data were collected. Table 2 summarises the language profiles of the bilingual group according to students' responses concerning the language spoken with their family.

Table 2. Distribution of language profiles

\begin{tabular}{llll}
\hline $\mathrm{N}$ & L1 & L2 & L3 \\
\hline 5 & Romanian & Spanish & English \\
3 & Arabic & Spanish & English \\
2 & Portuguese & Spanish & English \\
1 & Russian & Spanish & English \\
1 & Georgian & Spanish & English \\
1 & Spanish & Armenian & English \\
1 & Armenian & Spanish & English \\
\hline
\end{tabular}

\subsection{Data Collection Instruments and Procedures}

A background questionnaire and a lexical availability task were used as instruments for data collection and were the same for the groups participating in the study. The background questionnaire included questions to obtain information on learners' biographical factors such as age, sex, nationality, family language, language/s spoken at home, and previous experience with English language. The lexical availability included six prompts traditionally used in lexical availability studies: 'Animals', 'Food and Drink', 'The School', 'Town', 'Countryside' and 'Hobbies'.

Two members of our research team (GLAUR) moved to each school to administer the tasks to students in their 
own classrooms, in the presence of their teachers. Students answered to the questionnaire in the first place. Then, they were asked to write down as many words as came to mind in response to each prompt in the lexical availability task. The time allowed for each prompt was two minutes (12 minutes in total). To calculate the totals, means, standard deviations, and maximum and minimum values of lexical availability output for each group, we typed learners' lemmatised word responses into Excel files. In the lemmatisation, we adopted the criteria applied in Jiménez Catalán and Agustín Llach (2017). These criteria were: (i) correction of spelling errors, (ii) deletion of unintelligible words, and Spanish L1 words, (iii) repetion of the same word was counted only once, (iv) lexical phrases as well as compound words were lemmatized as one lexical unit and counted as one word (e.g. coffee break).

With regard to the identification of most productive and least productive prompts, we used WordSmith Tools (Version 6), which provide us with the alphabetic and frequency ranks for each prompt. Finally, the most and least productive prompts were submitted to the VocabProfile programme to obtain L3 and L2 frequency profiles. This programme allowed us to classify L3 and L2 learners' word responses according to frequency in the English language on the basis of BNC-COCA corpora into four bands: the 1,000 most frequent words in English (K1), the second 1,000 most frequent words (K2), the most frequent words at the academic level (AWL), and the words not found in any of the other lists (Off-list). Prominent vocabulary researchers have considered word frequency to be an important dimension of vocabulary knowledge, to the point of being a proxy for lexical richness and language proficiency: The higher the number of infrequent words known by the learners, the higher their lexical sophistication and their proficiency in the target language (Schmitt, 2010; Meara, Lightbown \& Halter, 1997; Nation \& Waring, 1997).

\section{Results}

Our first research question aimed at ascertaining whether there were quantitative differences between L3 and L2 English learners. The descriptive statistics for the overall lexical availability output for each group, as shown in Table 3, indicated that L2 learners produced a higher number of words than did L3 learners. The independent-samples t-test used to compare the overall means in lexical availability output proved the existence of significant differences between the two groups $(\mathrm{t}(23,211)=2,199, \mathrm{p}=0,038$, two-tailed). A closer inspection of the data revealed that one student in the L3 group, compared to nine students in the L2 group, produced over 100 words in the lexical availability task.

Table 3. Descriptive statistics for lexical availability output in the L3 and the L2

\begin{tabular}{llllll}
\hline $\mathrm{N}$ & Total & Min & Max & Mean & SD \\
\hline English L3 & 1,143 & 42 & 104 & 81 & 15.95 \\
14 & & & & & \\
English L2 & 1,641 & 67 & 176 & 117 & 38.10 \\
14 & & & & & \\
\hline
\end{tabular}

The different patterns observed in the overall means are corroborated when we examine students' individual means, which were calculated by counting the number of words that each student produced in response to each prompt in each group. As Table 4 reflects, on average, the L2 group produced a higher number of words than did the $\mathrm{L} 3$ group in all prompts.

Table 4. Means for English L3 and L2 according to the prompt

\begin{tabular}{lllllllll}
\multicolumn{2}{l}{$\begin{array}{l}\text { Bilingual group (English L3) } \\
\text { Min }\end{array}$} & Max & Mean & \multicolumn{2}{l}{ SD } & & Prompt & \multicolumn{4}{l}{ Monolingual group (English L2) } \\
& 33 & 18.79 & 6.104 & 'The School' & 12 & 33 & 23.79 & 6.216 \\
6 & 21 & 16.07 & 4.269 & 'Animals' & 9 & 29 & 19.43 & 6.321 \\
9 & 31 & 15.79 & 5.494 & 'Food \& Drink' & 6 & 39 & 19.57 & 9.002 \\
10 & 28 & 15.57 & 4.653 & 'Town' & 12 & 28 & 19.79 & 5.632 \\
0 & 23 & 9.57 & 5.707 & 'Countryside' & 5 & 26 & 16.43 & 7.920 \\
8 & 26 & 14.14 & 4.538 & 'Hobbies' & 9 & 30 & 18.21 & 7.413 \\
\hline
\end{tabular}


An independent-samples t-test was conducted to compare the number of words produced by the L3 and L2 groups for the six prompts. The scores for the prompts 'The School' $(\mathrm{t}(26)=2,147, \mathrm{p}=0,041$, two-tailed), 'Town' ( $\mathrm{t}(25,01)=2,158, \mathrm{p}=0,041$, two-tailed), 'Hobbies' $(\mathrm{t}(21,544)=1,753, \mathrm{p}=0,094$, two tailed) and 'Countryside' ( $\mathrm{t}(23,63)=2,628, \mathrm{p}=0,015$, two-tailed) were significant.

We now move to our second research question in which we queried whether there would be qualitative differences in the words produced by the L3 and the L2 groups. The parameters used in the analysis were the most and least productive prompts for each group, followed by lexical sophistication as shown by the number of infrequent words appearing in the production of each group. Due to space limitations, we will restrict our analysis to the words produced by learners for the most and least productive prompts, respectively.

Table 5 shows the ranking of prompts from those produced most to least often by each group. This comparison indicates the existence of a great similarity, as the most productive and least productive prompts were 'The School' and 'Countryside', respectively, in the two groups. Similarly, there was similarity regarding the prompt 'Hobbies', with identical ranking position in the two groups. The greatest differences were observed in the prompts 'Animals' and 'Town': The former was in the second position in the L3 group, compared to being in the fourth position in the L2 group, whereas the latter appeared in the fourth position in the L3 group but in the second position in the L2 group.

Table 5. Ranking of prompts in the L3 and the L2

\begin{tabular}{lllll}
\hline Rank & L3 & Tokens & L2 & Tokens \\
\hline 1 & The School & 238 & The School & 333 \\
2 & Animals & 215 & Town & 277 \\
3 & Food \& Drink & 208 & Food \& drink & 274 \\
4 & Town & 192 & Animals & 272 \\
5 & Hobbies & 182 & Hobbies & 255 \\
6 & Countryside & 108 & Countryside & 230 \\
\hline
\end{tabular}

To determine the similarities or differences in terms of lexical sophistication as measured by infrequent words, we submitted the total production of word types in each cohort to the analysis of VocabProfile programme, which provided us with the distribution of words into frequency bands. Table 6 shows the percentages for 'The School', the most productive prompt, and 'Countryside', the least productive prompt in both groups. With regard to 'The School', we observed similarities in the two groups, both in the predominance of word responses within the band of 1000 most frequent words, as well as in a similar percentage in the 2000 most frequent words. However, the comparison also revealed different tendencies. Firstly, we observed that the L3 group produced more words within the first and second most frequent bands $(1 \mathrm{~K}+2 \mathrm{~K})$; specifically, $63.48 \%$ of the words in the L3 group compared to $56.14 \%$ in the L2 group. Secondly, the percentages show that the L2 group produced more words within the AWL and Off-list bands than did the L3 group.

Focusing now on 'Countryside', we observed the predominance of word responses within the 1000 most frequent words, as well as a similar percentage of 2000 of the most frequent words in the two groups. However, with regard to the AWL band, the percentages of words produced were higher in the L3 group than they were in the L2 group.

Table 6. Frequency distributions

\begin{tabular}{lllll}
\hline & The School & & Countryside & \\
& L3 $(\%)$ & L2 $(\%)$ & L3 $(\%)$ & L2 $(\%)$ \\
\hline K1 & 46.09 & 39.88 & 51.55 & 45.26 \\
K2 & 17.39 & 16.26 & 23.71 & 22.63 \\
AWL & 5.22 & 7.98 & 5.15 & 2.92 \\
Off-the list & 31.30 & 35.89 & 19.59 & 29.20 \\
\hline
\end{tabular}




\section{Discussion}

Our aim was to study the vocabulary performances of immigrant students who were learners of English as an L3 compared to learners of English as an L2 at the same course level and from the same community. We wanted to explore how bilingualism may affect lexical ability output in terms of the number of words retrieved, as well as regarding lexical sophistication as measured by a higher number of infrequent words.

The first research question aimed to ascertain whether immigrant students, bilingual in their home language and in Spanish, would produce more English words in a lexical availability task than would non-immigrant students who were learners of English as an L2. The results of the present study did not prove the advantage of bilingualism concerning L3 lexical availability production, as the monolingual group retrieved more words in the lexical availability task. In this respect, the present study corroborates the findings obtained in two distinct bilingual contexts with different combinations of languages and data collection tasks. One bilingual context was Iran, in the study conducted by Ghezlou, Koosha and Lotfi (2018), in which it was found that the monolingual group (Persian speaking) produced a higher number of words in English translation tasks than did the bilingual group (Azeri-Persian). The other was in the north of Spain, where Agustín Llach (2017) observed that the monolingual group (Spanish), compared to the bilingual group (Basque-Spanish), retrieved a significantly higher number of words in a lexical availability task consisting of four prompts: 'Hobbies', 'Town', 'Countryside', and 'Food and Drink'. This finding is particularly relevant for the present study because the data collection instrument, the prompts, the educational grade and the learners' age ranges were identical. Furthermore, the present study included two additional prompts, 'The School' and 'Animals', which also confirmed the same pattern: Monolinguals produced more words than did bilinguals, although the results proved to be significant only for 'The School'. The coincidence of the results is important considering that the studies mentioned were based on bilingual samples from different contexts.

The findings of the present study provide insights into the vocabulary performance of bilingual immigrant L3 learners with different language combinations. Furthermore, the results are based on data collected from schools in the same community, rather than on data collected in two different communities. Despite these important differences, there is a remarkable similarity in the results that warrants careful interpretation. One interpretation might be related to memory and the psycholinguistic processes involved in lexical access. The lower lexical availability of immigrant L3 learners might be due to slow access in the activation of their L3 lexicon in a time-controlled task in which learners were asked to write down as many words associated with a prompt that came to their mind. This interpretation is grounded in the Competition Model (see Colomé, 2001; Kroll, Bobb, Misra, \& Guo, 2008), in which it is advocated that lexical access is non-language specific and, as a result, there is competition among the languages known by the speaker in the process of accessing words (see Costa \& Santesteban, 2004). Furthermore, in the comparison of the vocabulary size of monolingual and bilingual children, Allman (2005) found vocabulary overlap in the two languages. This assumption has implications for the interpretation of the results of the present study, and for L3 vocabulary studies in general because, rather than considering learners' production in English and taking this the norm for reference, the combination of languages known by the learners should be considered. In other words, the evaluation of the bilingual learners' lexicon would consist of all the words known in the three languages rather than on the vocabulary production in the L3 language. In light of this interpretation, we cannot conclude that L3 learners have a lower lexical competence in the English language than do L2 learners. Further studies in which L3 and L2 learners are provided with lexical availability tasks in the languages they know are needed. Only then we could ascertain whether there are differences in the lexical availability output of the two groups.

Another possible explanation might be the disadvantaged socio-economic position of immigrant families in society (Note 1), which is connected to underachievement in the three cognitive domains assessed (science, reading and mathematics). In addition, according to the PISA 2015 report (OECD, 2016), students with an immigrant background score below non-immigrant students in most countries. This situation was mentioned by Cenoz (2003: 75) in her review of the effects of bilingualism on L3 acquisition: “...it is important to remember that immigrant learners may also be at a disadvantage because of their socioeconomic status or other social and cultural factors." In turn, the low scores might be due to the problems and difficulties that immigrant students had to overcome in primary and secondary education in the host country, in comparison to their peers. As Cenoz (2003: 74) observed, “...immigrant students often face more difficulties and obtain lower scores at school than local children." In our view, the disadvantaged socioeconomic position, together with the difficulties immigrant students might have encountered at school, might have resulted in negative attitudes and a lack of motivation to learn English as an L3 which, in turn, might explain their lower lexical availability production. This is a hypothesis that requires further research. 
The second research question aimed to explore whether bilingualism would be associated with a higher percentage of infrequent words in the lexical production of immigrant L3 learners compared to L2 learners. The findings obtained confirm the lower production of L3 learners and the higher production of L2 ones. The application of the Vocabulary Profile to the words retrieved by the two groups in response to the most productive prompt, 'The School', revealed more infrequent words in the responses of the L2 group. This suggests a higher vocabulary level in relation to this lexical field. The opposite was the case for 'Countryside', as the L3 group retrieved a higher percentage of infrequent words than did the L2 group. This finding corroborates the results obtained by Agustín Llach (2017) in English L3 in her comparison of the lexical availability performance in English L3 and L2 with a sample of Basque-Spanish bilinguals and Spanish monolinguals. She found a tendency for the bilingual group to retrieve a higher percentage of infrequent words in the four prompts under examination ('Hobbies', 'Town', 'Countryside' and 'Food and drink'). In accordance with our previous interpretation, our finding regarding 'Countryside' would suggest a higher vocabulary knowledge related to this lexical field. However, we cannot draw definite conclusions in this regard without a thorough analysis of the frequency profiles of the remaining prompts.

\section{Conclusion}

The study used a lexical availability task to compare the vocabulary performance of immigrant students who were learners of English as an L3 with that of non-immigrant students, who were learners of English as an L2. The bilingual advantage was not proved, as the L2 group produced a greater number of words. Furthermore, lexical sophistication was higher in this group, as observed in the higher percentages of infrequent words in the lexical availability output of the L2 group compared to the L3 group. The results proved to be significant both overall and considering learners' responses to five of the six prompts included in the lexical availability task. In addition, they were relevant for the study of lexical complexity and richness in monolingual and bilingual immigrant English learners, as a higher percentage of infrequent words in the lexical availability task suggests a lower level in the sample of immigrant L3 learners. However, although important for vocabulary research and for foreign language education, the results are only representative of the schools and the community in which the research was conducted. Therefore, further lexical availability studies should be carried out, and these should include larger samples of L3 learners from immigrant populations, particularly from public schools with different social contexts. A tendency for immigrant students to be in the public school system, as well as to show variation according to educational contexts, has been observed (García Castaño \& Rubio Gómez, 2015). With regard to contexts, it is important to conduct research in situations of additive bilingualism rather than of subtractive bilingualism, as may be the case for bilingual immigrants. In this situation, results may be related to other variables such as the sociolinguistic and educational contexts rather than to bilingualism (cf. Cenoz \& Hoffman, 2003, p. 3). In this regard, and as one of our reviewers suggested, future research should include information on the socio-economic position of immigrant families as to ascertain whether the lower performance of L3 immigrant students in the lexical availability task is due to cognitive processes or to their sociolinguistic background. Similarly, future studies should look at samples with a combination of language typologies, as there is some evidence that the combination of languages (Maluch et al., 2015) and typologies (Cenoz, 2001; Martínez-Adrián \& Gallardo del Puerto, 2017) can influence the results. Finally, lexical availability results in the L3 and the L2 would be more reliable with the inclusion of standardised language and vocabulary tests to complement to teachers' reports on the English language level of their students. Its inclusion would allow us to correlate lexical availability and language level in the comparisons of bilingual L3 learners and monolingual L2 learners. This would provide us with a more accurate picture of the realities of bilingualism and multilingualism, and their relationship to foreign language achievement in school contexts.

\section{Acknowledgements}

This work is framed under a research project on the English available lexicon of EFL learners in school contexts thanks to the support of the Spanish Ministerio de Economía y Competitividad, under Grant (FFI 2013-47707-P). We are grateful to the students, teachers and headmasters of the schools who collaborated in this study.

\section{References}

Agustín Llach, M. P. (2017). The impact of bilingualism on the acquisition of an additional language: Evidence from lexical knowledge, lexical fluency, and (lexical) cross-linguistic influence. International Journal of Bilingualism, 1-13.

Allman, B. (2005). Vocabulary size and accuracy of monolingual and bilingual preschool children. In J. Cohen, K. T. McAlister, K. Rolstad, \& J. MacSwan (Eds.), Proceedings of the 4th International Symposium on Bilingualism (pp. 58-77). Somerville, MA: Cascadilla Press. 
Cenoz, J. (2003). The additive effect of bilingualism on third language acquisition: A review. International Journal of Bilingualism, 7(1), 71-87. https://doi.org/10.1177/13670069030070010501

Cenoz, J. (2001). The effect of linguistic distance, L2 status and age on cross-linguistic influence in L3 acquisition. In J. Cenoz, B. Hufeisen, \& U. Jessner (Eds.), Cross-linguistic influence in third language acquisition: psycholinguistic perspectives (pp. 8-20). Clevedon: Multilingual Matters. https://doi.org/ 10.21832/9781853595509

Cenoz, J., \& Gorter, D. (2013). Towards a Plurilingual Approach in English Language Teaching: Softening the Boundaries between Languages. TESOL Quarterly, 47(3), 591-599. https://doi.org/10.1002/tesq.121

Cenoz, J., \& Hoffmann, C. (2003). Acquiring a third language: What role does bilingualism play? International Journal of Bilingualism, 7(1), 1-5. https://doi.org/10.1177/13670069030070010101

Colomé, A. (2001). Lexical activation in bilinguals' speech production: Language specific or language-independent. Journal of Memory and Language, 45, 721-736. https://doi.org/10.1006/jmla. 2001.2793

Costa, A., Albareda, B., \& Santesteban, M. (2008). Assessing the presence of lexical competition across languages: Evidence from the Stroop task. Bilingualism: Language and Cognition, 11, 121-131. https://doi.org/10.1017/S1366728907003252

Costa, A., \& Santesteban, M. (2004). Lexical Access from language switching in highly proficient bilinguals and L2 learners. Journal of Memory and Language, 50, 491-511. https://doi.org/10.1016/j.jml.2004.02.002

Cvekić, I. (2016). Third language vocabulary acquisition. The influence of Serbian and Hungarian as native languages on the English language. Colloquium Philologies, 1(1), 63-75.

Dibaj, F. (2011). Vocabulary learning: a comparison of learners of English as a second and third language. ARAL, 34(2), 193-215. https://doi.org/10.1075/aral.34.2.04dib

García Castaño, F. J., \& Rubio Gómez, M. (2015). Immigrant Students at School in Spain: Constructing a Subject of Study. Due Domovini-Two Homelands, 41, 35-47.

Ghezlou, M., Koosha, M., and Lotfi, A. R. (2018). Acquisition of adjective placement by L3 learners: Evidence for the L2 status factor. International Journal of Applied Linguistics and English Literature, 7(2), 175-184. https://doi.org/10.7575/aiac.ijalel.v.7n.2p.175

Jessner, U. (2008). Teaching third languages: Findings, trends and challenges. Language Teaching, 41(1), 15-56. https://doi.org/10.1017/S0261444807004739

Jiménez Catalán, R. M. (2017). Estudios de disponibilidad léxica en español y en inglés: revisión de sus fundamentos empíricos y metodológicos. Revista Nebrija de Lingüistica Aplicada, 22, 16-31.

Jiménez Catalán, R.M., \& Agustín Llach, M.P. (2017). CLIL or Time? Lexical profiles of CLIL and non-CLIL EFL learners. System, 66, 87-99. https://doi.org/10.1016/j.system.2017.03.016

Kassaian, Z. \& Esmae'li, S. (2011). The effect of bilinguality on L3 breadth of vocabulary knowledge and Word Reading skill. Theory and Practice in Language Study, 1(8), 966-974. https://doi.org/10.4304/tpls. 1.8.966-974

Keikhaie, Y., Khoshkhoonejad, A., Mansoorzaden, N., \& Panahandeh, E. (2015). Bilingualism and Vocabulary Learning: A Comparison between Baluchi and Persian EFL Learners. Journal of Education and Learning, 9(3), 183-189.

Keshavarz, M. H., \& Astaneh, H. (2004). The impact of bilinguality on the learning of English vocabulary as a foreign language (L3). International Journal of Bilingual Education and Bilingualism, 7(4), 295-302. https://doi.org/10.1080/13670050408667814

Kroll, J., Bobb, S., Misra, M., and Guo, T. (2008). Language selection in bilingual speech: Evidence for inhibitory processes. Acta Psychologica, 128, 416-430. https://doi.org/10.1016/j.actpsy.2008.02.001

Lipińska, D. (2017). The influence of age and L2 on third language acquisition in a corporate environment. Theory and Practice of Second Language Acquisition, 3(1), 7-27.

Maluch, J. T., et al., (2015). The effect of speaking a minority language at home on foreign language learning. Learning and Instruction, 36, 76-85. https://doi.org/10.1016/j.learninstruc.2014.12.001 
Martínez-Adrián, M., \& Gallardo-del-Puerto, F. (2017). The effects of language typology on L2 lexical availability and spelling accuracy. International Journal of English Studies, 17(2), 63-79. https://doi.org/10.6018/ijes/2017/2/256411

Meara, P., Lightbown, P. M., \& Halter, R. (1997). (1997). Classroom as lexical environments. Language Teaching Research, 1(1), 28-46. https://doi.org/10.1177/136216889700100103

Molnár, T. (2008). Second language versus third language vocabulary acquisition: A comparison of the English lexical competence of monolingual and bilingual students. Toronto Working Papers in Linguistics (TWPL), $33,1-16$.

Nation, P., Waring, R. (1997). Vocabulary size, text coverage and word lists. In N. Schmitt, \& M. McCarthy (Eds.), Vocabulary Description, acquisition and pedagogy (pp. 6-19). Cambridge: Cambridge University Press.

OECD. (2016). PISA 2015 Results (Volume I): Excellence and Equity in Education, PISA. Paris: OECD Publishing. https://doi.org/10.1787/9789264266490-en

OECD. (2018). Equity in Education: Breaking Down Barriers to Social Mobility, PISA. Paris: OECD Publishing. https://doi.org/10.1787/9789264073234-en

Richards, J. C., \& Schmidt, R. (2010) Longman Dictionary of Language Teaching and Applied Linguistics. Harlow: Longman.

Schmitt, N. (2010). Research vocabulary: A vocabulary research manual. Basingstoke: Palgrave Press. https://doi.org/10.1057/9780230293977

Secretaría General Técnica (2017) (Ed.). Datos y cifras. Curso escolar 2017/2018. Madrid: Ministerio de Educación, Cultura y Deporte.

Thomas, J. (1988). The role played by metalinguistic awareness in second and third language learning. Journal of Multilingual and Multicultural Development, 9(30), 235-247. https://doi.org/10.1080/01434632.1988. 9994334

Wei, L. (2003). Activation of lemmas in the multilingual mental lexicon and transfer in third language acquisition. In J. Cenoz, B. Hufeisen, \& U. Jessner (Eds.), The multilingual lexicon (pp. 57-70). Dordrecht: Kluwer. https://doi.org/10.1007/978-0-306-48367-7_5

Zare, M., \& Davoudi-Mobarakeh, S. (2013) Effects of bilingualism on L3 vocabulary learning among Iranian EFL learners. GEMA Online Tm Journal of Language Studies, 13(1), 127-138.

\section{Note}

Note 1. According to the most recent PISA report (OECD, 2018), socioeconomically disadvantaged students are more likely to have an immigrant background or to speak a language at home that is different from the one spoken at school.

\section{Copyrights}

Copyright for this article is retained by the author(s), with first publication rights granted to the journal.

This is an open-access article distributed under the terms and conditions of the Creative Commons Attribution license (http://creativecommons.org/licenses/by/4.0/). 